\title{
Qualidade de pedúnculos de caju submetidos à aplicação pós-colheita de cálcio e armazenados sob refrigeração
}

\author{
Raimundo Wilane de Figueiredo(1), Franco Maria Lajolo(2), Ricardo Elesbão Alves ${ }^{(3)}$, \\ Heloísa Almeida Cunha Filgueiras ${ }^{(3)}$, Geraldo Arraes Maia ${ }^{(1)}$ e Paulo Henrique Machado de Sousa ${ }^{(4)}$
}

\begin{abstract}
(1)Universidade Federal do Ceará, Caixa Postal 12.168, CEP 60356-000 Fortaleza, CE. E-mail: figueira@ufc.br, gmaia@secrel.com.br (2)Universidade de São Paulo, Caixa Postal 66.083, CEP 05508-900 São Paulo, SP. E-mail: fmlajolo@usp.br (3)Embrapa Agroindústria Tropical, Caixa Postal 3.761, CEP 60.511 Fortaleza, CE. E-mail: elesbão@cnpat.embrapa.br, heloisa@cnpat.embrapa.br (4)Universidade Federal de Viçosa, Av. P.H. Rolfs s/no, CEP 36571-000 Viçosa, MG. E-mail: phenriquemachado@gmail.com
\end{abstract}

\begin{abstract}
Resumo - O objetivo deste trabalho foi avaliar os efeitos da aplicação de cálcio pós-colheita nas características químicas, físico-químicas e nos teores de cálcio em pedúnculos de cajueiro-anão precoce CCP-76, submetidos a armazenamento refrigerado sob atmosfera modificada. Os cajus foram imersos em água e em soluções com diferentes concentrações de cloreto de cálcio $(0,5,1 \mathrm{e} 2 \% \mathrm{p} / \mathrm{v})$, por dois minutos. Os cajus foram acondicionados em bandejas de isopor, envolvidos em filme de PVC e armazenados a $5 \pm 1^{\circ} \mathrm{Ce} 88 \pm 3 \%$ de umidade relativa, durante 25 dias. Os teores de sólidos solúveis e açúcares solúveis diminuíram durante o armazenamento. Os pedúnculos de caju, independentemente da dose de cálcio, apresentaram tendência à diminuição da acidez e da vitamina $\mathrm{C}$ com o armazenamento, enquanto o pH apresentou um pequeno e gradual crescimento. Não houve variação nas antocianinas, nos pseudofrutos de caju tratados com cálcio. Verificaram-se pequenas reduções nas frações fenólicas menos polimerizadas, durante o armazenamento. O cálcio aplicado nas doses de 0,5 e $2 \%$ aumentou os teores de cálcio nos pedúnculos até o $15^{\circ}$ dia, com diminuição posterior até o final do experimento.
\end{abstract}

Termos para indexação: Anacardium occidentale, qualidade pós-colheita, cloreto de cálcio.

\section{Quality of cashew pseudofruits treated with calcium at postharvest and stored under refrigeration}

\begin{abstract}
The objective of this work was to evaluate the effects of postharvest calcium applications on chemical and physico-chemical characteristics, quality atributes and calcium tissue concentration of early dwarf cashew pseudofruits (Anacardium occidentale L.), stored under refrigeration and modified atmosphere. The cashews were immersed in water and in different calcium chloride solution concentrations $(0.5,1$ and $2 \%(w / v))$ for two minutes. Cashews were put in polysterene trays, packed in polyvinyl chloride (PVC) and storaged at $5 \pm 1{ }^{\circ} \mathrm{C}$, $88 \pm 3 \% \mathrm{RH}$ for 25 days. The total soluble solids (Brix) and soluble sugars decreased during storage. The pseudofruits, independent of the chloride calcium concentration, showed a tendency to decrease the total titratable acidity and vitamin $\mathrm{C}$, and an increase of $\mathrm{pH}$ during storage. The anthocyanins content showed no variation in treated cashew pseudofruits. Small reductions in less polymerized polyphenolic fraction were observed during the storage period. The chloride calcium concentrations 0.5 and $2.0 \%$ slightly increased tissue calcium concentration until the $15^{\circ}$ storage day, and decreased, afterwards, until the end of the experiment.
\end{abstract}

Index terms: Anacardium occidentale, postharvest quality, calcium chloride.

\section{Introdução}

A conservação pós-colheita do pedúnculo do caju, à temperatura ambiente, não ultrapassa 48 horas, em razão de sua extrema suscetibilidade ao ataque de microrganismos, responsáveis pelo estabelecimento de um rápido processo fermentativo (Soares, 1986).

Entre os métodos de conservação disponíveis, a refrigeração é um dos mais utilizados e eficientes para o armazenamento de frutos e hortaliças (Chitarra \&
Chitarra, 2005). Atmosfera controlada ou modificada são utilizadas, principalmente, como complementos do abaixamento de temperatura, pois, na maioria das vezes, não produzem bons resultados individualmente (Alves, 1999).

O uso de filmes de plásticos é uma forma simples de assegurar a alta umidade relativa ao redor do produto, durante as operações de armazenamento, transporte e comercialização (Mattoo et al., 1975). O filme aumenta a resistência à passagem do vapor d'água, $\mathrm{O}_{2}$ e $\mathrm{CO}_{2}$, e 
produz uma microatmosfera com umidade relativa maior que a externa, que altera a taxa de transpiração, reduz a perda de água, retarda mudanças no teor de açúcares, na cor e na textura, e reduz as perdas de acidez, pela diminuição da atividade de enzimas relacionadas ao metabolismo respiratório. Kader (1992) afirma que a perda de clorofila e a biossíntese de carotenóides e antocianinas são diminuídas em frutas mantidas em atmosfera modificada.

A influência da aplicação de cálcio em frutos tem recebido atenção considerável, em razão dos efeitos positivos desse cátion no adiamento da maturação e da senescência - mediante a diminuição da respiração e da produção de etileno -, no controle de distúrbios fisiológicos e na conservação dos frutos (Poovaiah, 1986; Lurie \& Klein, 1992).

O objetivo deste trabalho foi avaliar o efeito da aplicação pós-colheita de cálcio, em diferentes concentrações, sobre as características químicas, físico-químicas, e sobre os teores de cálcio em pedúnculos de cajueiroanão precoce CCP-76, submetidos a armazenamento refrigerado sob atmosfera modificada.

\section{Material e Métodos}

Cajus do clone CCP-76, de um cultivo comercial em Mossoró, Rio Grande do Norte, foram colhidos aleatoriamente no estádio de maturidade comercial; os pseudofrutos apresentavam textura firme e cor laranjaescuro e foram selecionados quanto à uniformidade, em relação ao tamanho e ausência de deterioração. Os cajus foram selecionados, pré-resfriados a $22^{\circ} \mathrm{C}$ e imersos em solução de hipoclorito de sódio a $1 \%$ para desinfestação superficial. Em seguida, foram submetidos à aplicação de cálcio, durante dois minutos de imersão em soluções com $0,0,5,1$ e $2 \%$, de cloreto de cálcio, que continham $250 \mathrm{ppm}$ do espalhante adesivo Tween 80. Após secagem ao ar, os cajus de cada tratamento foram acondicionados em bandejas rasas de poliestireno, envolvidos em filme auto-adesivo de PVC flexível, com espessura de $15 \mu \mathrm{m}$, devidamente selados e identificados pelo tratamento correspondente, armazenados a $5 \pm 1^{\circ} \mathrm{C}$ e $88 \pm 3 \%$ UR, e avaliados por $0,5,10,15,20$ e 25 dias.

Após a remoção de amostras de epicarpo, para análise de antocianinas totais, os pedúnculos foram seccionados longitudinalmente em partes iguais e distribuídos, de acordo com o tratamento, em sacos transparentes de polietileno de baixa densidade $(27 \times 31 \mathrm{~cm})$, com fecho hermético, identificados e armazenados em ultrafreezer a $-80^{\circ} \mathrm{C}$ para análises posteriores.
Os pedúnculos foram desintegrados em centrífuga doméstica, e parte desse material foi submetido à liofilização, para a determinação de cálcio, e outra parte foi destinada, no primeiro dia de tomada de amostras, às análises de: $\mathrm{pH}$ (Association of Official Analytical Chemists, 1992); sólidos solúveis, (SS), por leitura em refratômetro digital Atago modelo PR-101; acidez total titulável (ATT), com solução de $\mathrm{NaOH} 0,1 \mathrm{~N}$, expressa como porcentagem de ácido málico (Instituto Adolfo Lutz, 2005); açúcares solúveis totais, determinados pelo método de Antrona (Southgate, 1991); vitamina C, determinada pelo do método titulométrico com DFI (Strohecker \& Henning, 1967); antocianinas totais (Francis, 1982); compostos fenólicos extraídos de acordo com Swain \& Hillis (1959), e dosados segundo Reicher et al. (1981). O cálcio total foi determinado por espectrometria de absorção atômica, após digestão nitroperclórica, conforme Sarruge \& Haag (1974), e o cálcio solúvel foi determinado conforme Siddiqui \& Bangerth (1995a, 1995b). O cálcio insolúvel foi obtido por diferença, e o porcentual de solubilização foi obtido por meio do quociente entre cálcio solúvel e cálcio total.

O delineamento experimental utilizado foi o inteiramente casualizado, em esquema fatorial 4 (concentrações de cloreto de cálcio) x 6 (tempos de armazenamento), com quatro repetições, com a unidade experimental composta por cinco cajus.

As análises foram realizadas com o programa SISVAR versão 3.01. A partir dos resultados das análises de variância, e tendo-se verificado a interação entre os fatores, o tempo foi desdobrado dentro de cada tratamento, e os resultados submetidos à regressão polinomial, considerando-se equações de até terceiro grau, conforme Banzatto \& Kronka (1992). O coeficiente de determinação mínimo para utilização das curvas foi de 0,70. Equações de grau superior a três foram consideradas como desvio de regressão e, nos casos em que apenas estas foram significativas, optouse por representar os valores médios dos tratamentos sem curva de ajuste.

\section{Resultados e Discussão}

As análises de variância, realizadas para as características sólidos solúveis e açúcares solúveis totais, indicaram interação significativa entre o tratamento com cálcio e o tempo de armazenamento dos pedúnculos de caju. 
Os teores de sólidos solúveis e açúcares solúveis totais apresentaram, em geral, ligeiros decréscimos ao longo do armazenamento (Figura 1). Isto pode ser atribuído ao consumo de açúcares via metabolismo respiratório.

Os dados registrados pela literatura, no que tange ao armazenamento de frutos tratados ou não com cálcio, mostram uma variação considerável dos teores de sólidos solúveis e açúcares solúveis totais, entre espécies e dentro de uma mesma espécie. Em pedúnculos de caju, Morais et al. (2002) não observaram diferença significativa de sólidos solúveis ao longo do armazenamento. Entretanto, Menezes (1992) trabalhou com pedúnculos de cajueiro comum e, nas mesmas condições de armazenamento usadas neste experimento, verificou aumento significativo de sólidos solúveis. Lima (1998) observou que em uvas 'Itália', o teor de sólidos solúveis totais se manteve estável durante o armazenamento, independentemente do tratamento com cálcio, porém,
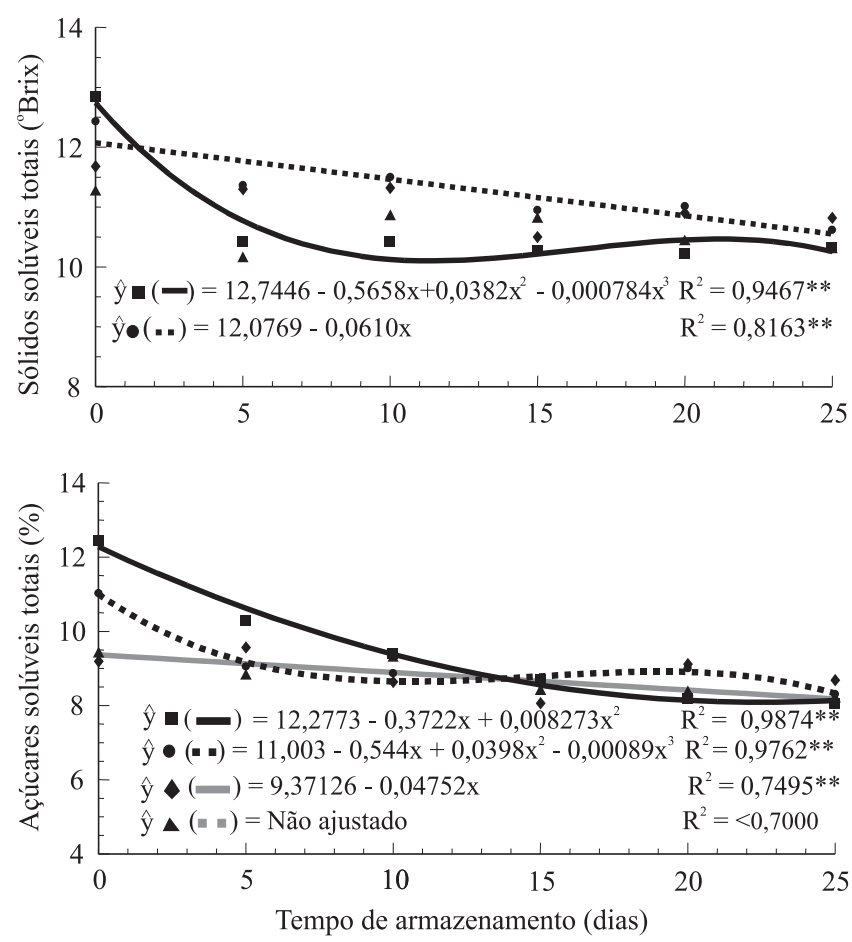

Figura 1. Sólidos solúveis e açúcares solúveis totais de pedúnculos de cajueiro-anão precoce $\mathrm{CCP}-76$, submetidos ao tratamento pós-colheita: controle ( $\bullet), 0,5 \%$ de cálcio $(\bullet)$, $1 \%$ de cálcio $(\)$ e $2 \%$ de cálcio $(\boldsymbol{\wedge})$, armazenados durante 25 dias sob atmosfera modificada, em temperatura de $5 \pm 1{ }^{\circ} \mathrm{Ce}$ umidade relativa de $88 \pm 3 \%$. **Significativo a $1 \%$ de probabilidade. em pêssego (Ochei et al., 1993), Kiwi (Gerasopoulos et al., 1996) e morango (García et al., 1996), os aumentos em sólidos solúveis, encontrados durante o armazenamento, foram retardados por aplicações de cálcio. Gonçalves et al. (1996), em trabalho realizado com limão 'Tahiti', observaram teores mais altos de sólidos solúveis nos frutos tratados com $2 \% \mathrm{de}^{\mathrm{CaCl}_{2} \mathrm{e}}$ valores inferiores e similares, respectivamente, para aqueles tratados com 1 e $3 \%$ de $\mathrm{CaCl}_{2}$.

Os pedúnculos de caju, independentemente da dose de cálcio utilizada, apresentaram variações significativas na acidez em função do tempo, com tendência à diminuição (Figura 2). Os teores médios de acidez total titulável variaram entre 0,26 e $0,30 \%$ de ácido málico, portanto, dentro da faixa indicada por diversos autores (Maia \& Soares, 1970; Moura Fé et al., 1972; Menezes, 1992). Em geral, o comportamento da ATT, ao longo do armazenamento obtido neste experimento, é semelhante àquele obtido por Morais et al. (2002), em trabalho
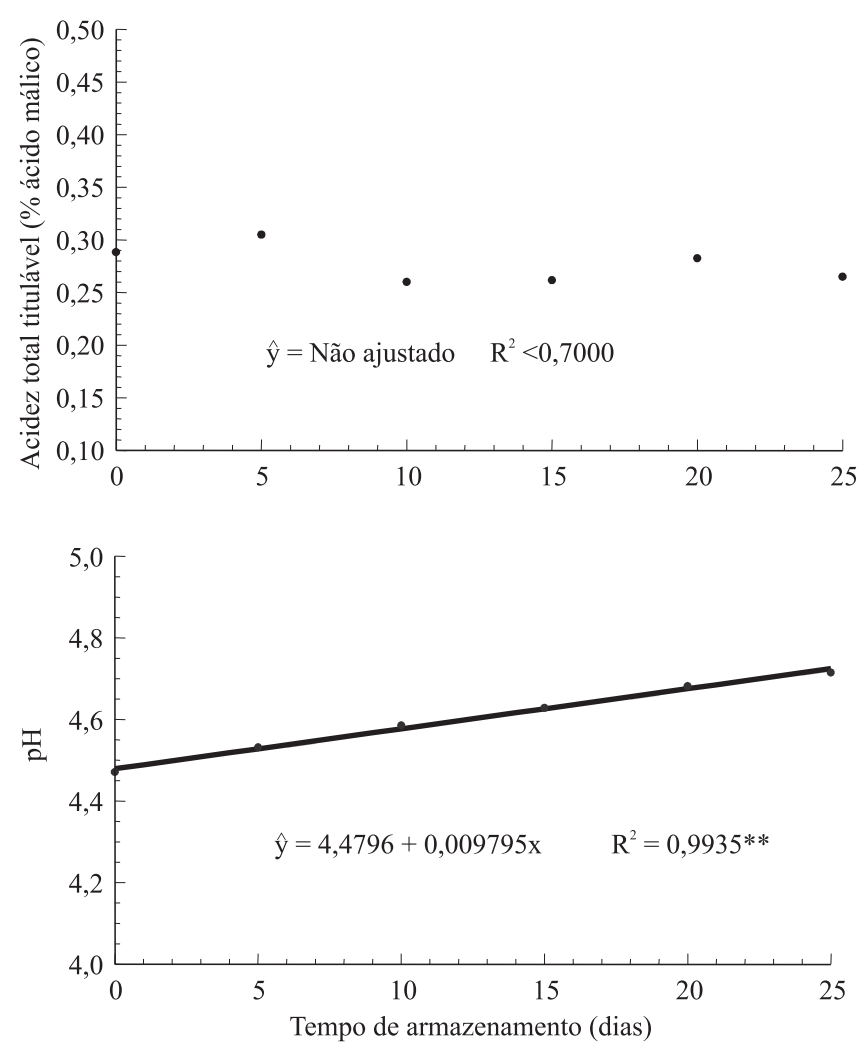

Figura 2. Acidez total titulável e pH, em pedúnculos de cajueiro-anão precoce CCP -76 armazenados durante 25 dias sob atmosfera modificada. ${ }^{*}$ Significativo a $1 \%$ de probabilidade. 
realizado com pedúnculos de cajueiro-anão precoce CCP-76.

No presente trabalho, a redução da atividade metabólica em conseqüência do abaixamento da concentração de oxigênio pelo uso da atmosfera modificada, não chegou a impedir que os ácidos orgânicos fossem utilizados como substratos respiratórios, de modo a causar reduções na acidez (Zagory \& Kader, 1988).

Em pedúnculos de caju, os tratamentos com cálcio não exerceram influência na acidez, durante o armazenamento. Segundo Lima (1998), os efeitos desses tratamentos sobre essa variável não são conclusivos. Em limão 'Tahiti' foi verificada a influência do cálcio (Gonçalves et al., 1996), porém, em morango, segundo García et al. (1996), similarmente ao caju, não foram encontradas diferenças significativas na ATT dos frutos imersos em solução de $\mathrm{CaCl}_{2}$, durante o armazenamento.

Com relação ao $\mathrm{pH}$, os pedúnculos de caju, independentemente do tratamento com cálcio, apresentaram um pequeno e gradual crescimento ao longo do armazenamento (Figura 2). Este comportamento é semelhante ao encontrado por Menezes (1992). Segundo Kays (1991), uma vez que a concentração de ácidos orgânicos totais tende a declinar, após a colheita e durante o armazenamento, o pH sofreria, por consequiência, uma elevação.

O teor de vitamina $\mathrm{C}$ total foi afetado, significativamente, pelo tempo de armazenamento, tendo havido oxidação desse componente durante o período experimental (Figura 3). Não houve efeito significativo do tratamento com cálcio, em relação a essa variável.

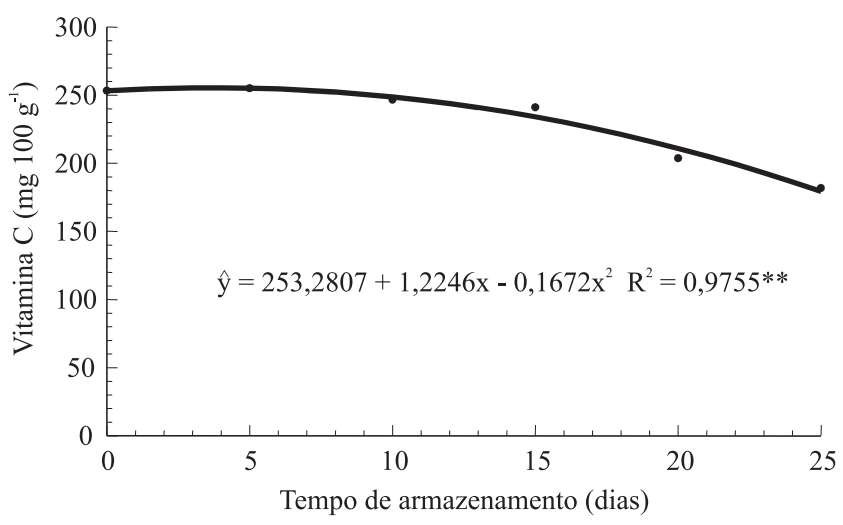

Figura 3. Vitamina $C$ total, em pedúnculos de cajueiro-anão precoce CCP-76 submetidos ao tratamento pós-colheita com cálcio e armazenados durante 25 dias sob atmosfera modificada. **Significativo a $1 \%$ de probabilidade.
A redução no teor de vitamina $\mathrm{C}$ total foi muito pequena até o 15o dia de armazenamento, e acentuou-se a partir daí, tendo atingido teor final $28 \%$ menor que o inicial. Resultados semelhantes foram constatados por Menezes (1992), em trabalhos realizados com pedúnculos de cajueiro comum, submetidos às mesmas condições de armazenamento, contudo sem o uso de cálcio. $\mathrm{O}$ autor, porém, encontrou uma degradação mais acentuada no oitavo dia de armazenamento.

Segundo Shewfelt (1986), a manutenção de umidade relativa alta, para prevenir o murchamento e perda de turgor, é efetiva em diminuir as perdas de ácido ascórbico e $\beta$-caroteno. Nesse sentido, Kader (1992) afirma que a modificação da atmosfera resulta numa maior retenção de ácido ascórbico, em razão, principalmente, da menor disponibilidade de $\mathrm{O}_{2}$ no interior da embalagem.

Watada (1987) cita que a despeito do baixo nível de $\mathrm{O}_{2}$ contribuir para diminuição das perdas de vitamina $\mathrm{C}$, teores elevados de $\mathrm{CO}_{2}$ no interior da embalagem acentuam essas perdas, em frutos como banana e maçã, o que pode ter ocorrido neste experimento, tendo-se em vista o não conhecimento da concentração de gases, após a modificação da atmosfera pelo uso de filme de PVC.

Chempakam (1983), em trabalho com ácido ascórbico oxidase em caju, observou um pequeno aumento na atividade dessa enzima, no final da fase de desenvolvimento, e sugeriu que o ligeiro aumento na oxidação do ácido ascórbico, durante a última semana de desenvolvimento, poderia ser atribuído à ação de outras oxidases. Nesse sentido, não se pode afirmar qual a enzima responsável pela degradação da vitamina $\mathrm{C}$ em pedúnculo de caju, sobretudo em razão da riqueza do pedúnculo em substratos dessas enzimas oxidativas.

A despeito da diminuição do teor de vitamina $\mathrm{C}$ total, em pedúnculos de caju, mesmo aos 25 dias de armazenamento, os valores médios encontrados ainda podem ser considerados elevados, quando comparados aos frutos tradicionalmente considerados como fonte de vitamina $\mathrm{C}$, como, por exemplo, a laranja.

Apesar de não ter sido verificada a interação significativa entre as doses de cálcio e o tempo de armazenamento para o teor de antocianinas, estes fatores mostraram significância quando avaliados individualmente (Figura 4).

Praticamente não houve variação nos teores de antocianinas totais nos pedúnculos tratados com $\mathrm{CaCl}_{2}$. Porém, esses apresentaram teores menores em pelo 
menos $10 \%$ em relação aos não tratados. Observou-se uma tendência ao declínio dos teores de antocianinas totais, no decorrer do armazenamento, acentuado entre o 10 o e 15 o dia do experimento (Figura 4). Constatou-se uma redução de aproximadamente 50\% nos teores de antocianinas totais, ao final do experimento. A despeito desse índice, pelos resultados dos testes praticados na avaliação de senescência, ao término do ensaio, pôdese verificar que os pedúnculos ainda permaneceram em condições de comercialização, porque a velocidade de senescência dos seus tecidos foi muito baixa ao longo do armazenamento.

Os principais fatores que influenciam a cor das antocianinas são: sua natureza química, concentração, presença de pigmentos, $\mathrm{pH}$, copigmentos e, algumas vezes, a presença de íons metálicos (Stafford, 1990). $\mathrm{O} \mathrm{pH}$ destaca-se como o mais importante fator que afeta a cor das antocianinas (Mazza \& Brouillard, 1987).
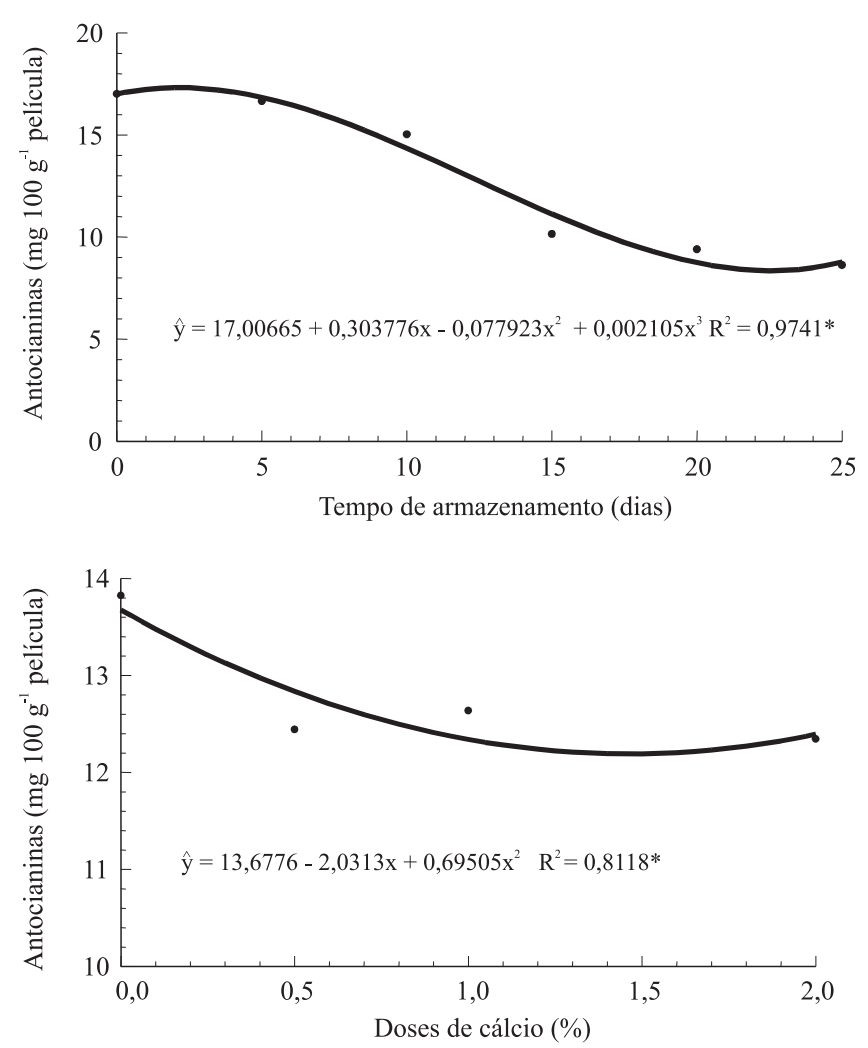

Figura 4. Antocianinas totais, em pedúnculos de cajueiro-anão precoce $\mathrm{CCP}-76$ submetidos ao tratamento pós-colheita com cálcio e armazenados durante 25 dias sob atmosfera modificada. ${ }^{*}$ Significativo a $5 \%$ de probabilidade.
As soluções de antocianinas apresentam uma coloração vermelha mais intensa, em $\mathrm{pH}$ abaixo de 3. Quando o pH é aumentado para a faixa de 4 a 5 , a coloração vermelha tende a desaparecer. Aumentos adicionais de pH levam as antocianinas a apresentar uma coloração azulada, e, após armazenamento ou aquecimento, amarelada (Stringheta, 1991). Neste experimento, observouse um pequeno aumento do $\mathrm{pH}$, ao longo do armazenamento, o que pode, em parte, ter contribuído para a desestabilização da cor vermelha do pedúnculo.

A diminuição dos teores de antocianinas coincidiu com a degradação de vitamina $\mathrm{C}$, ao longo do tempo de armazenamento, o que sugere uma possível interação entre os dois compostos. A combinação de antocianinas e vitamina $C$ é mutuamente destrutiva em presença de oxigênio (Talcott et al., 2003).

Houve efeito significativo da interação entre os fatores doses de cálcio e tempo de armazenamento, sobre os fenólicos poliméricos, oligoméricos e dímeros, e o efeito do tempo de armazenamento foi significativo em todas as concentrações de cálcio.

Em todas as concentrações de cálcio aplicadas, verificou-se uma diminuição dos teores de fenólicos poliméricos, com o decorrer do tempo de armazenamento (Figura 5). Os pedúnculos tratados com cálcio apresentaram teores de fenólicos poliméricos similares aos não tratados, no final do período de armazenamento.

A despeito da ocorrência de flutuações, há tendência de redução nos teores de fenólicos oligoméricos com o decorrer do armazenamento (Figura 5), e os teores desses compostos são pelo menos $18 \%$ mais elevados que os dos poliméricos, ao final do período de armazenamento. Os fenólicos dímeros foram semelhantes aos oligoméricos, porém superiores em $23 \%$ aos poliméricos, no final do período de armazenamento.

Em geral, constataram-se reduções nas frações fenólicas menos polimerizadas, durante o tempo de armazenamento dos pedúnculos. Nesse sentido, não se pode afirmar se houve ou não perda de adstringência, pois, embora tenha havido redução dos fenólicos oligoméricos e dímeros, considerados responsáveis pela adstringência de muitos frutos, ocorreu também diminuição no teor de fenólicos poliméricos. O teor de açúcares solúveis totais diminuiu ligeiramente com o decorrer do armazenamento, o que pode ter contribuído para provável redução do mascaramento dos fenólicos responsáveis pela adstringência. Sugere-se, portanto, a realização de estudos de avaliação sensorial de pedúnculos de caju armazenados, a fim de que sejam fornecidos mais subsídios para a avaliação da adstringência. 
Morais et al. (2002), em trabalho realizado com pedúnculos de cajueiro-anão precoce CCP-76, armazenados sob atmosfera modificada e refrigeração, verificaram uma pequena redução nos teores de todas as frações de fenólicos analisadas a partir do quinto dia. Menezes (1992) verificou uma tendência à diminuição das frações dímeras e oligoméricas, ao longo do armazenamento de pedúnculos de cajueiro-comum, entretanto, contrariamente à presente pesquisa, os teores da fração polimérica aumentaram.

Houve interação significativa entre tempo de armazenamento e tratamento com cálcio para cálcio total, cálcio solúvel e cálcio insolúvel.
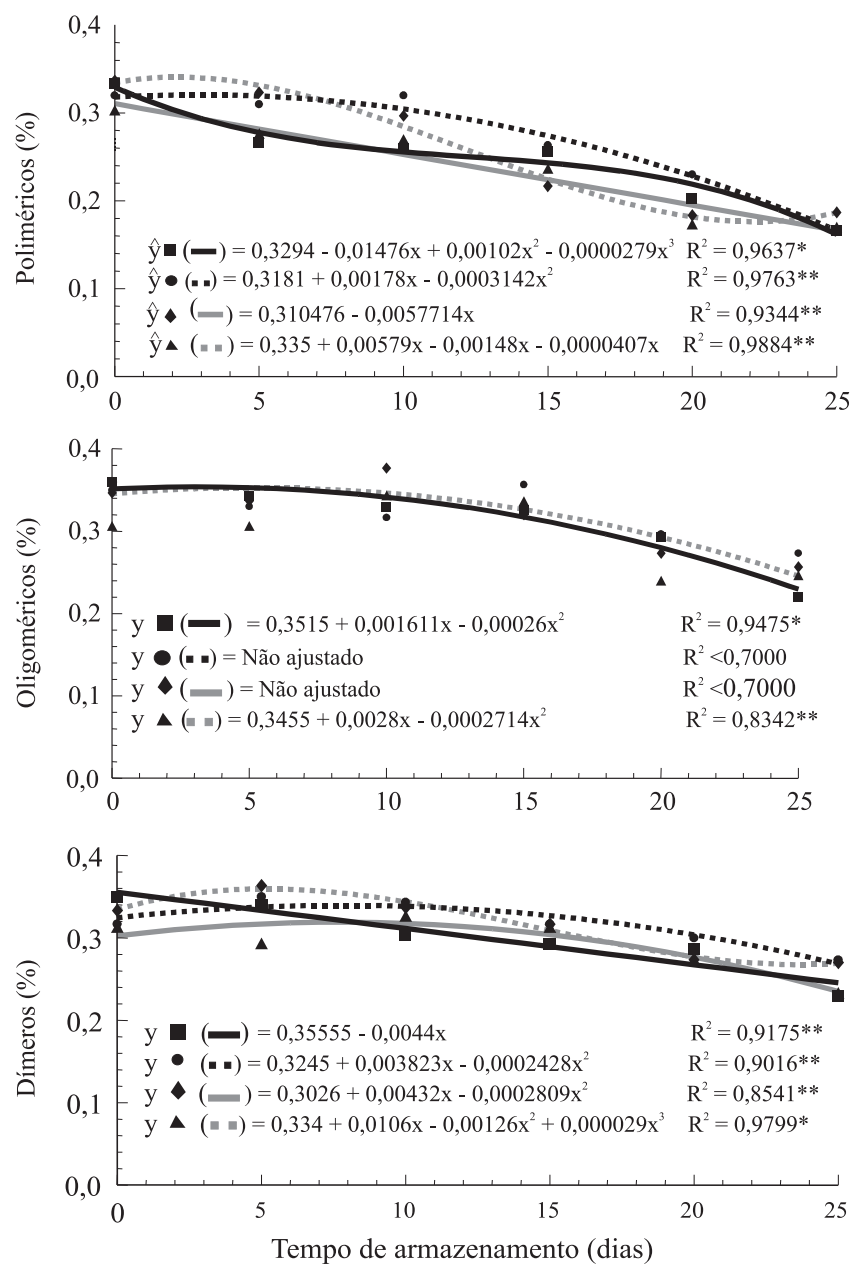

Figura 5. Compostos fenólicos poliméricos, oligoméricos e dímeros, em pedúnculos de cajueiro-anão precoce CCP-76 submetidos ao tratamento pós-colheita com cálcio e armazenados durante 25 dias sob atmosfera modificada.

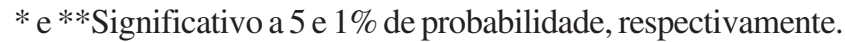

Os pedúnculos de caju, submetidos ao tratamento com 0,5 e $2 \%$ de cálcio, apresentaram um aumento no teor de cálcio total até o 15o dia de armazenamento, para, em seguida, diminuir ligeiramente até o final do experimento. Acréscimos nos teores de cálcio total ocorreram com o aumento da concentração de cálcio utilizada, e os resultados obtidos no final do experimento, para os pedúnculos que receberam a concentração máxima $(2 \%)$, foram mais que o dobro daqueles que não receberam cálcio (Figura 6).
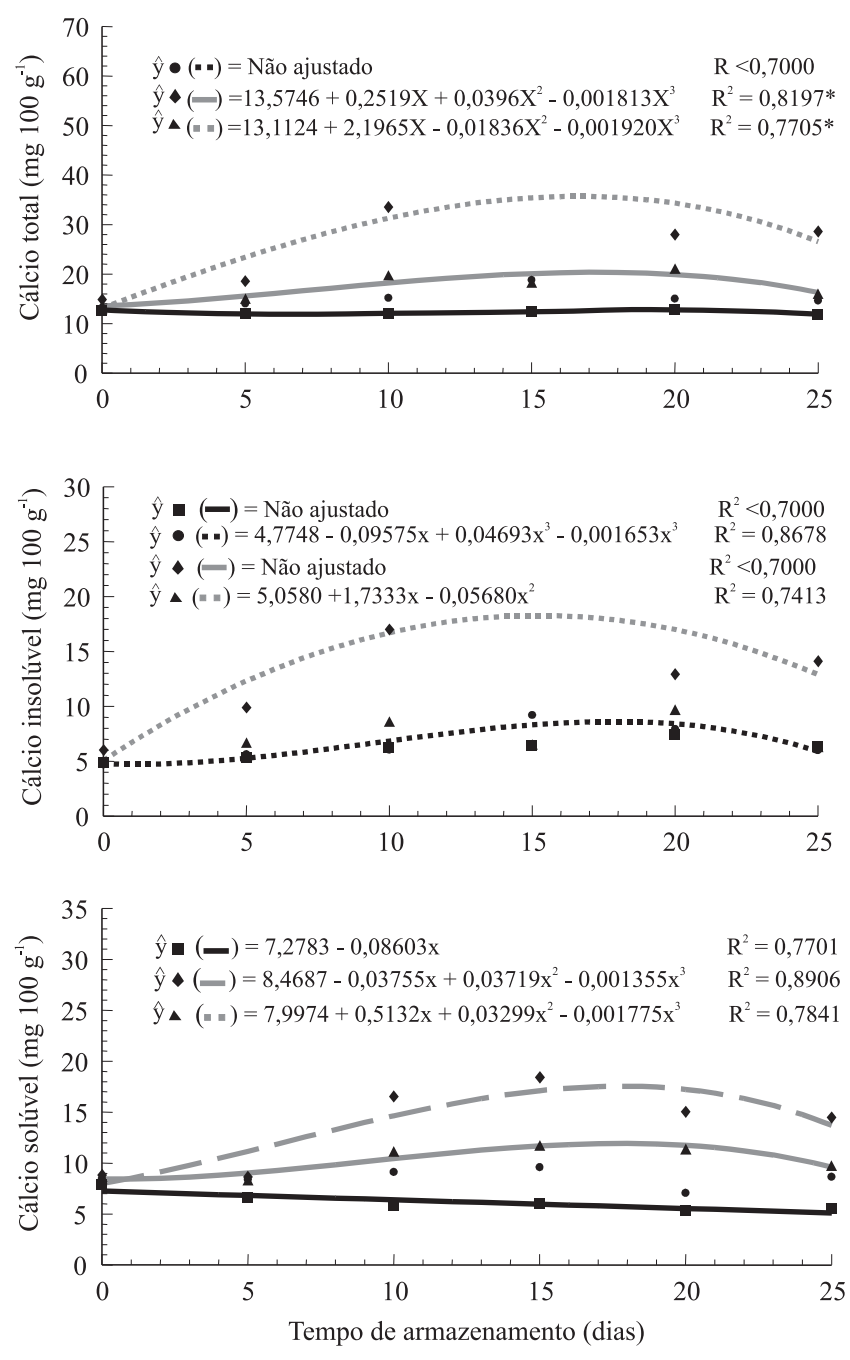

Figura 6. Cálcio total, insolúvel e solúvel, de pedúnculos de cajueiro-anão precoce CCP-76 submetidos ao tratamento pós-colheita com cálcio e armazenados durante 25 dias sob atmosfera modificada. * e **Significativo a 5 e $1 \%$ de probabilidade, respectivamente. 
Comportamento semelhante ao cálcio total ocorreu para a variável cálcio solúvel e cálcio insolúvel, cujos resultados estão representados na Figura 6.

Em alguns frutos, segundo Alves (1999), a espessura do mesocarpo oferece uma barreira física que muitas vezes impede a absorção de cálcio, quando aplicado em pós-colheita, principalmente sem o auxílio de tratamentos suplementares (pressão reduzida), como foi constatado em mamão por Qiu et al. (1995).

Podem-se verificar aumentos nos teores de cálcio solúvel e insolúvel com o aumento das doses de cálcio, que mostram, porém, tendência à saturação a partir do 15o dia de armazenamento, particularmente quando se aplica a dose de $2 \%$ de cálcio.

Os pedúnculos que receberam a maior concentração de cálcio (2\%) apresentaram mais que o dobro do teor de cálcio insolúvel das testemunhas, ao final do experimento. É provável, portanto, que a aplicação pós-colheita de cálcio tenha favorecido uma maior ligação de cálcio nas paredes celulares. Esses resultados são coerentes com os valores de firmeza, que aumentam ligeiramente até o 15- dia de armazenamento, para depois declinar até o final do experimento, assumindo ainda valores $4,38 \%$ mais elevados do que a testemunha.

\section{Conclusões}

1. O uso do cálcio pós-colheita pouco influencia as características de qualidade do pedúnculo de caju CCP-76, durante o armazenamento refrigerado associado à atmosfera modificada.

2. O conteúdo de antocianinas é inversamente proporcional às concentrações cálcio aplicadas em pós-colheita, independentemente do tempo de armazenamento.

3. O tratamento pós-colheita com cálcio a $2 \%(\mathrm{p} / \mathrm{v})$ promove maior incorporação do cálcio nos tecidos e, conseqüentemente, uma maior resistência pós-colheita.

\section{Referências}

ALVES, R.E. Qualidade de acerolas submetidas a diferentes condições de congelamento, armazenamento e aplicação pós-colheita de cálcio. 1999.135p. Tese (Doutorado) - Universidade Federal de Lavras, Lavras.

ASSOCIATION OF OFFICIAL ANALYTICAL CHEMISTS (Washington, Estados Unidos). Official methods of analysis of the Association of Official Analytical Chemists. $12^{\text {th }}$ ed. Washington, 1992. 1115p.
BANZATTO, D.A.; KRONKA, S. do N. Experimentação agrícola. Jaboticabal: Funep, 1992. 247p.

CHEMPAKAM, B. Distribution of ascorbic acid and ascorbic acid oxidase activity in the developing cashew apple (Anacardium occidentale L.). Journal of Horticultural Science, v.58, p.447448, 1983.

CHITARRA, M.I.F.; CHITARRA, A.B. Pós-colheita de frutos e hortaliças: fisiologia e manuseio. Lavras: Esal/Faepe, 2005. 785p.

FRANCIS, F.J. Analysis of anthocyanins. In: MARKAKIS, P. (Ed.). Anthocyanins as food colors. New York: Academic Press, 1982. p.181-207.

GARCÍA, J.M.; HERRERA, S.; MORILLA, A. Effects of postharvest dips in calcium chloride on strawberry. Journal of Agricultural and Food Chemistry, v.44, p.30-33, 1996.

GERASOPOULOS, D.; CHOULIARAS, V.; LIONAKIS, S. Effects of preharvest calcium chloride sprays on maturity and storability of Hayward kiwifruit. Posharvest Biology and Technology, v.7, p.65-72, 1996.

GONÇALVES, N.B.; CARVALHO, V.D. de; BOTELHO, L. Avaliação do potencial de armazenamento do limão 'Tahiti' (Citrus latifolia Tanaka) com a utilização de baixas temperaturas e aplicação de cálcio. I. Alterações físico-químicas e qualitativas. Revista Brasileira de Fruticultura, v.18, p.175-191, 1996.

INSTITUTO ADOLFO LUTZ. Métodos físico-químicos para análise de alimentos. 4.ed. Brasília: Anvisa, 2005. 1018p.

KADER, A.A. Postharvest biology and technology: an overview. In: KADER, A.A. Postharvest technology of horticultural crops. Oakland: University of California, 1992. p.15-20. (Publication, 3311).

KAYS, S.J. Postharvest physiology of perishable plant products. New York: Van Nostrand Reinhold, 1991. 532p.

LIMA, M.A.C. Desenvolvimento, maturação e armazenamento refrigerado de uva 'Itália' sob influência do cálcio. 1998. 110p. Dissertação (Mestrado) - Universidade Federal do Ceará, Fortaleza.

LURIE, S.; KLEIN, J.D. Calcium and heat treatments to improve storability of Anna apples. HortScience, v.27, p.36-39, 1992.

MAIA, G.A.; SOARES, J.B. Gradientes de acidez, açúcares e ácido ascórbico no caju. Boletim Cearense Agronômico, v.11, p.25-29, 1970.

MATTOO, A.K.; MURATA, T.; PANTASTICO, E.B.; CHACHIN, K.; OGATA, K.; PHAN, C.T. Chemical changes during ripening and senescence. In: PANTASTICO, E.B. Postharvest physiology, handling and utilization of tropical and subtropical fruits and vegetables. Westport: Avi Pub. Co., 1975. p.103-127.

MAZZA, G.; BROUILLARD, R. Recent developments in the stabilization of anthocyanins in food products. Food Chemistry, v.25, p.207-225, 1987.

MENEZES, J.B. Armazenamento refrigerado de pedúnculo do caju (Anacardium occidentale L.) sob atmosfera ambiental e modificada. 1992. 102p. Dissertação (Mestrado) - Universidade Federal de Lavras, Lavras.

MORAIS, A. de S.; MAIA, G.A.; FIGUEIREDO, R.W. de; ALVES, R.E.; FILGUEIRAS, H.A.C.; MOURA, C.F.H. Armazenamento 
refrigerado sob atmosfera modificada de pedúnculos de cajueiroanão precoce dos clones CCP-76, end-157, end-183 e end-189. Revista Brasileira de Fruticultura, v.24, p.647-650, 2002.

MOURA FÉ, J.A.; HOLANDA, L.F.F. de; MARTINS, C.B.; MAIA, G.A. Características químicas do hipocarpo de caju (Anacardium occidentale L.). Ciência Agronômica, v.2, p.103-108, 1972.

OCHEI, C.O.; BASIOUNY, F.M.; WOODS, F.M. Calcium-mediated postharvest changes in storageability and fruit quality of peaches. Proceedings of the Florida State Horticultural Society, v.106, p.266-269, 1993.

POOVAIAH, B.W. Role of calcium in prolonging storage life of fruits and vegetables. Food Technology, v.40, p.86-88, 1986.

QIU, Y.X.; NISHINA, M.S.; PAULL, R.E. Papaya fruit-growth, calcium-uptake, and fruit ripening. Journal of the American Society for Horticultural Science, v.120, p.246-253, 1995.

REICHER, F.; SIERAKOWSKI, M.R.; CORREA, J.B.C. Determinação espectrofotométrica de taninos pelo reativo fosfotúngstico-fosfomolíbdico. Arquivos de Biologia e Tecnologia, v.24, p.407-411, 1981.

SARRUGE, J.R.; HAAG, H.P. Análises químicas em plantas. Piracicaba: Esalq-USP, 1974. 56p.

SHEWFELT, R.L. Postharvest treatment for extending the shelf life of fruits and vegetables. Food Technology, v.40, p.70-78, 1986.

SIDDIQUI, S.; BANGERTH, F. Differential effect of calcium and strontium on flesh firmness and properties of cell-walls in apples. Journal of Horticultural Science, v.70, p.949-953, 1995b.
SIDDIQUI, S.; BANGERTH, F. Effect of preharvest of calcium on flesh firmness and cell-wall composition of apples-influence of fruit size. Journal of Horticultural Science, v.70, p.263-269, 1995a.

SOARES, J.B. O caju. In: O caju: aspectos tecnológicos. Fortaleza: BNB, 1986. p.37-123.

SOUTHGATE, D.A.T. Determination of food carbohydrates. London: Elsevier Applied Science, 1991. 232p.

STAFFORD, H.A. Flavonoid metabolism. Boca Raton: CRC Press, 1990. 286p.

STRINGHETA, P.C. Identificação da estrutura e estudo da estabilidade das antocianinas extraídas de inflorescência de capim-gordura (Melinis minutiflora Pal. de Beauv.). 1991. 138p. Tese (Doutorado) - Universidade Estadual de Campinas, Campinas.

STROHECKER, R.; HENNING, H.M. Analisis de vitaminas: metodos comprobados. Madrid: Paz Montalvo, 1967. 428p.

SWAIN, T.; HILLIS, E.E. The phenolic constituents of Prunus domestica. II. The analysis of tissues of the 'Victoria' plum tree. London: Journal of Food Science and Technology, v.10, p.135144, 1959.

TALCOTT, S.T.; BRENES, C.H.; PIRES, D.M.; POZO-INSFRAN, D. del. Phytochemical stability and color retention of copigmented and processed muscadine grape juice. Journal of Agricultural and Food Chemistry, v.51, p.957-963, 2003.

WATADA, A.E. Vitamins. In: WEICHMANN, J. Postharvest physiology of vegetables. NewYork: M. Dekker, 1987. p.455-467.

ZAGORY, D.; KADER, A.A. Modified atmosphere packaging of fresh produce. Food Technology, v.42, p.70-77, 1988.

$\overline{\text { Recebido em } 13 \text { de julho de } 2006 \text { e aprovado em } 14 \text { de fevereiro de } 2007}$ 